Janusz Dąbrowski*

\title{
Accuracy Standards of Tying the Horizontal and Vertical Control Network to the National Geodetic Control Network
}

\section{Introduction}

To adjust the survey results of multi-row networks the Gauss-Markov model can be used, including accuracy weight matrix for the values observed, as well as including the apparent observational equations for the coordinates of tie points. To the apparent observational equations the relevant accuracy weights are assigned for the analysed coordinate points or their covariance matrices. Many authors of scientific papers use for that purpose the sequential adjustment of measurement results, i.e. the adjustment carried out in a few stages. By foreign authors, there are the works of Baardy [2], Teunissen [14] and Rao [13]. By domestic authors, there are the papers of Adamczewski [1], Baran [3], Gaździcki [7], Kadaj [8], Wiśniewski [15] and Kamiński [9]. Many computer programmes, e.g. GOENET [8], use this procedure to adjust measurement results of the multirow control networks.

The issue of the estimation of the horizontal and vertical control point coordinates in tying to national geodetic control networks is similar to multirow networks adjustment but specific allocation of these networks set down different conditions of tying them to national geodetic control networks. This problem, in relation to determination of point displacement, was worked on in Canada by Chrzanowski [4] and in Germany by Pelzer [10]. Similar deliberations were made nationally by Czaja [6] and Prószyński and Kwaśniak [12]. The deliberations included in this publication will only be referred to three thematically nearest positions, i.e. Czaja [5], Prószyński [11] and Wiśniewski [16]. In paper [5] the author proposes to include the observations of connecting national geodetic control network points to the adjustement of horizontal and vertical control network. For the coordinates of national geodetic control points the author proposes to juxtapose the pseudo-observation equations including their ccovariance matrices. Prószyński [11] in his paper presents the method of tying the horizontal and vertical control networks to the national geodetic

* AGH University of Science and Technology, Faculty of Mining Surveying and Environmental Engineering, Department of Geomatics, Krakow, Poland 
control networks with use of Helmert transformation parameters. In the first stage, the horizontal and vertical control network, along with selected points of national geodetic control network, is freely adjusted in local system. In the second stage, the local system is transformed into national system, on the basis of previously estimated transformation parameters for adjustment points, namely turn and displacement. Wiśniewski [16] in his paper deals with observation results adjustment in geodetic networks. Deliberations included in Chapter 6 refer to the adjustment of results with the use of sequential method, i.e. carried out for different stages of geodetic network measurement. The gist of this method is to include in each stage the adjustment of results obtained in previous stages. Wiśniewski [16] proved that the formulated pseudo-observation equations for the point coordinates and their covariance matrices, obtained in the preceding stages, have identical estimates to the adjustment of the whole geodetic network in one stage.

Horizontal and vertical control networks are used for marking out structures in the field, therefore the coordinates of their points have to be marked with high accuracy. The accuracy of horizontal and vertical control networks is at least by one range higher than the one of national geodetic control networks. Tying the horizontal and vertical control networks to the coordinates of national geodetic control points is done by means of geodetic tie construction. Tie construction consists of a selected group of horizontal and vertical control network points and national geodetic control network points, in which the angles and lenghts marked by these points are measured.

The adjustment of measurement results in tie construction leads to determination of coordinate estimates of the selected horizontal and vertical control points and the national geodetic control points as well as their covariance matrices. For the estimation of point coordinates in tie construction covariance matrix must be used for the coordinates of selected national geodetic control network points.

Final adjustment of measurement results in the horizontal and vertical control network cannot be affected by inaccuracy of the national geodetic control point coordinates, included in tie construction.

To formulate the accuracy criteria for tying horizontal and vertical control network it is necessary, for tie construction, to introduce separate formulas for estimation of point coordinates and their covariance matrices of the horizontal and vertical control network and the national geodetic control network. The introduction of these formulas is done by way of solving the system of four matrix equations, which result from the reciprocal of properly defined block matrix.

The criterion for the proper way of tying the horizontal and vertical control network is assumed as the relation of standard deviation value for the intervals between points in tie construction to the medium standard deviation of the sides lenght measurement in this construction. Value of the standard deviation is determined on the basis of the variance coefficient obtained from the estimation of points coordinates in tie construction and the variance included in the weight matrix for 
the measured lenghts. On the basis of this relation, three methods of tying horizontal and vertical control networks to the national coordinate system have been proposed.

The proposed methods of tying the horizontal and vertical control network can be used in marking out the structures in small areas as well as to mark out border markers of the residential plots in the field.

The practical application of the proposed algorithm for the determination of proper method of tying the horizontal and vertical control network, along with the interpretation of calculations results, is illustrated in the final part of this thesis in the form of numerical example.

\section{Theoretical Foundations of Gauss-Markov Model (L, AX, G) with Random Parameters}

It is assumed that $\mathbf{L}$ is a vector of the observed random variables, the mean value of which can be descibed with the use of the established linear $\mathbf{A X}$ models, where $\mathbf{X}$ represents the vector of the estimated parameters, and $\mathbf{A}$ represents the matrix of known coefficients in estimated parameters. In geodetic networks the values of these coefficients are the partial derivatives values of the observed elements (angles and lenghts) in relation to coordinates of points that specify these elements. The estimate parameters, on the other hand, are coordinate differentials of the national gedetic control points of tying and coordinate differentials of the horizontal and vertical control networks which are subject to connection.

It is assumed that the vector of estimated parameters $\mathbf{X}$ is also a random variable with covariance matrix $\mathbf{C}$.

To the observed values the condition is applied that matrix $\mathbf{G}$ is a conditional covariance matrix of the observations $\mathbf{L}$ with established parameters $\mathbf{X}$, namely $\mathbf{H}=V(\mathbf{L} \backslash \mathbf{X})$.

Considering the above assumptions, the conditional covariance matrix of the observations $\mathbf{L}$ is determined according to the dependancy [13]:

$$
V(\mathbf{L})=E[V(\mathbf{L} \backslash \mathbf{X})]+V\left(E(\mathbf{L} \backslash \mathbf{X})=\mathbf{G}+V(\mathbf{A} \mathbf{X})=\mathbf{G}+\mathbf{A} \mathbf{C} \mathbf{A}^{T}\right.
$$

In order to divide the process of differentials estimation to the horizontal and vertical control points coordinates to the process of differentials estimation of national geodetic control network points coordinates, with established covariance matrix $\mathbf{C}$, the coefficients matrix $\mathbf{A}$ has to be divided into two parts, namely matrices $\mathbf{A}_{1}$ and $\mathbf{A}_{2}$. Matrix $\mathbf{A}_{1}$ represents the coefficients of the national geodetic control point coordinates differentials, while $\mathbf{A}_{2}$ matrix represents the horizontal and vertical control points coordinates differentials. Simultaneously the estimated parameters $\mathrm{X}$ are subject to the analogical division into $\mathbf{X}_{1}$ and $\mathbf{X}_{2}$. 
Considering the above notations, the observational equations for the tie construction can be presented in the following block matrices formula:

$$
\left[\begin{array}{cc}
\mathbf{A}_{1} & \mathbf{A}_{2} \\
\mathbf{I} & \mathbf{0}
\end{array}\right] \times\left[\begin{array}{l}
\mathbf{X}_{1} \\
\mathbf{X}_{2}
\end{array}\right]=\left[\begin{array}{l}
\mathbf{L} \\
\mathbf{0}
\end{array}\right]
$$

For the equations (2) covariance matrix is defined in form of the following block matrix:

$$
\operatorname{cov}\left(\mathbf{L} ; \mathbf{X}_{1}\right)=\left[\begin{array}{cc}
\mathbf{G} & \mathbf{0} \\
\mathbf{0} & \mathbf{C}
\end{array}\right]
$$

where:

G - a conditional covariance matrix of observations $\mathbf{L}$ with established parameters,

C - a covariance matrix for multidimensional random variable that represents coordinates of the national geodetic control network points.

After carrying out the principle of the smallest quare sum of random deviations for the system (2), including covariance matrix (3), the normal equations system is presented in form of block matrices $[6,16]$ :

$$
\left[\begin{array}{cc}
\mathbf{A}_{1}^{T} \mathbf{G}^{-1} \mathbf{A}_{1}+\mathbf{C}^{-1} & \mathbf{A}_{1}^{T} \mathbf{G}^{-1} \mathbf{A}_{2} \\
\mathbf{A}_{2}^{T} \mathbf{G}^{-1} \mathbf{A}_{1} & \mathbf{A}_{2}^{T} \mathbf{G}^{-1} \mathbf{A}_{2}
\end{array}\right] \times\left[\begin{array}{l}
\mathbf{X}_{1} \\
\mathbf{X}_{2}
\end{array}\right]=\left[\begin{array}{cc}
\mathbf{A}_{1}^{T} \mathbf{G}^{-1} & \mathbf{C}^{-1} \\
\mathbf{A}_{2}^{T} \mathbf{G}^{-1} & \mathbf{0}
\end{array}\right] \times\left[\begin{array}{l}
\mathbf{L} \\
\mathbf{0}
\end{array}\right]
$$

In order to solve the normal equations system (4), with the division of estimated parameters into differentials vectors $\boldsymbol{X}_{1}$ and $\boldsymbol{X}_{2^{\prime}}$ it is necessary to determine the reciprocal of the block matrix that exists in the product with these parameters. To simply the analitical conversion for the block matrix elements the following notation is assumed:

$$
\left[\begin{array}{cc}
\mathbf{A}_{1}^{T} \mathbf{G}^{-1} \mathbf{A}_{1}+\mathbf{C}^{-1} & \mathbf{A}_{1}^{T} \mathbf{G}^{-1} \mathbf{A}_{2} \\
\mathbf{A}_{2}^{T} \mathbf{G}^{-1} \mathbf{A}_{1} & \mathbf{A}_{2}^{T} \mathbf{G}^{-1} \mathbf{A}_{2}
\end{array}\right]=\left[\begin{array}{cc}
\mathbf{N}_{1} & \mathbf{N}_{12} \\
\mathbf{N}_{12}^{T} & \mathbf{N}_{2}
\end{array}\right]
$$

The reciprocal of block matrix (5) is defined with use of the following condition:

$$
\left[\begin{array}{cc}
\mathbf{N}_{1} & \mathbf{N}_{12} \\
\mathbf{N}_{12}^{T} & \mathbf{N}_{2}
\end{array}\right] \times\left[\begin{array}{cc}
\mathbf{H}_{1} & \mathbf{H}_{12} \\
\mathbf{H}_{12}^{T} & \mathbf{H}_{2}
\end{array}\right]=\left[\begin{array}{ll}
\mathbf{I} & \mathbf{0} \\
\mathbf{0} & \mathbf{I}
\end{array}\right]
$$


Realisation of the condition (6) leads to four matrix equations system in the following form:

$$
\begin{aligned}
& \mathbf{N}_{1} \mathbf{H}_{1}+\mathbf{N}_{12} \mathbf{H}_{12}^{T}=\mathbf{I} \\
& \mathbf{N}_{1} \mathbf{H}_{12}+\mathbf{N}_{12} \mathbf{H}_{2}=\mathbf{0} \\
& \mathbf{N}_{12}^{T} \mathbf{H}_{1}+\mathbf{N}_{2} \mathbf{H}_{12}^{T}=\mathbf{0} \\
& \mathbf{N}_{12}^{T} \mathbf{H}_{12}+\mathbf{N}_{2} \mathbf{H}_{2}=\mathbf{I}
\end{aligned}
$$

Solving the above equation system leads to the following matrix formula $\mathbf{H}_{1}, \mathbf{H}_{2}$ and $\mathbf{H}_{12}$ :

$$
\begin{gathered}
\mathbf{H}_{1}=\left(\mathbf{N}_{1}-\mathbf{N}_{12} \mathbf{N}_{2}^{-1} \mathbf{N}_{12}^{T}\right)^{-1} \\
\mathbf{H}_{2}=\left(\mathbf{N}_{2}-\mathbf{N}_{12}^{T} \mathbf{N}_{1}^{-1} \mathbf{N}_{12}\right)^{-1} \\
\mathbf{H}_{12}=-\mathbf{N}_{1}^{-1} \mathbf{N}_{12} \times\left(\mathbf{N}_{2}-\mathbf{N}_{12}^{T} \mathbf{N}_{1}^{-1} \mathbf{N}_{12}\right)^{-1}
\end{gathered}
$$

On the basis of formulas (8), (9) and (10) for the reciprocal of block matrix (6), solution of the equation system (4) can be written in the following explicit form:

$$
\left[\begin{array}{l}
\hat{\mathbf{X}}_{1} \\
\hat{\mathbf{X}}_{2}
\end{array}\right]=\left[\begin{array}{ll}
\mathbf{H}_{1} & \mathbf{H}_{12} \\
\mathbf{H}_{12}^{T} & \mathbf{H}_{2}
\end{array}\right] \times\left[\begin{array}{cc}
\mathbf{A}_{1}^{T} \mathbf{G}^{-1} & \mathbf{C}^{-1} \\
\mathbf{A}_{2}^{T} \mathbf{G}^{-1} & \mathbf{0}
\end{array}\right] \times\left[\begin{array}{l}
\mathbf{L} \\
\mathbf{0}
\end{array}\right]
$$

The derived formula (11) enables to estimate seperately the differentials to national geodetic control points coordinates, in form of vector $\hat{\mathbf{X}}_{1}$, and the differentials to approximate coordinates of the horizontal and vertical control points, in form of vector $\hat{\mathbf{X}}_{2}$.

After realization of proper matrix products in the formula (11) for the first row of block matrix $\mathbf{H}$, vector $\hat{\mathbf{X}}_{1}$ is expressed by the following dependence:

$$
\hat{\mathbf{X}}_{1}=\left(\mathbf{H}_{1} \mathbf{A}_{1}^{T} \mathbf{G}^{-1}+\mathbf{H}_{12} \mathbf{A}_{2}^{T} \mathbf{G}^{-1}\right) \times \mathbf{L}
$$

Replacing the above dependence by the formula (8) and extracting matrix $\mathbf{H}_{1}$ from brackets we get final formula for estimated differentials to national geodetic control points coordinates, which is:

$$
\hat{\mathbf{X}}_{1}=\mathbf{H}_{1}\left(\mathbf{A}_{1}^{T} \mathbf{G}^{-1}-\mathbf{N}_{12} \mathbf{N}_{2}^{-1} \mathbf{A}_{2}^{T} \mathbf{G}^{-1}\right) \times \mathbf{L}
$$


After getting matrix product (11) for the second row of matrix $\mathbf{H}$ and after performing similar transformations like in formula (13), vector $\mathbf{X}_{2}$ is determined by the following relation:

$$
\hat{\mathbf{X}}_{2}=\mathbf{H}_{2}\left(\mathbf{A}_{2}^{T} \mathbf{G}^{-1}-\mathbf{N}_{12}^{T} \mathbf{N}_{1}^{-1} \mathbf{A}_{1}^{T} \mathbf{G}^{-1}\right) \times \mathbf{L}
$$

On account of the fact that the coordinates of national geodetic control points, included in the process of tying, are never corrected with the estimated differentials in form of vector $\hat{\mathbf{X}}_{1}$, therefore their values will be only used for estimation of random deviations for values observed in the tie construction. If the estimated differentials to the approximate coordinates of horizontal and vertical control network points, represented by vector $\hat{\mathbf{X}}_{2}$, are added to the approximate coordinates of points, established at the stage of just aposing the observational equations, we get the most probable coordinates of those points in the national system.

A very important problem in the presented process of estimation is the inaccuracy evaluation of vector $\hat{\mathbf{X}}_{2}$. Variance of vector $\hat{\mathbf{X}}_{2}$ can be written in form of a general definition in the following form [13]:

$$
V\left(\hat{\mathbf{X}}_{2}\right)=E\left\{\left[\hat{\mathbf{X}}_{2}-E\left(\hat{\mathbf{X}}_{2}\right)\right] \times\left[\hat{\mathbf{X}}_{2}-E\left(\hat{\mathbf{X}}_{2}\right)\right]^{T}\right\}
$$

After inserting to the above dependence the formula for vector estimate, the variance of this estimate is expressed by the relation:

$$
\begin{aligned}
& V(\hat{\mathbf{X}})= \\
& =E\left\{\left[\mathbf{H}_{2}\left(\mathbf{A}_{2}^{T} \mathbf{G}^{-1}-\mathbf{N}_{12}^{T} \mathbf{N}_{1}^{-1} \mathbf{A}_{1}^{T} \mathbf{G}^{-1}\right) \times \mathbf{L}-\mathbf{X}_{2}\right] \times\left[\mathbf{H}_{2}\left(\mathbf{A}_{2}^{T} \mathbf{G}^{-1}-\mathbf{N}_{12}^{T} \mathbf{N}_{1}^{-1} \mathbf{A}_{1}^{T} \mathbf{G}^{-1}\right) \times \mathbf{L}-\mathbf{X}_{2}\right]^{T}\right\}
\end{aligned}
$$

If the vector of absolute terms $\mathbf{L}$ is replaced by the expression containing the matrices from the process of estimation as a sum of model values of the observed quantities $\left(\mathbf{A}_{2} \hat{\mathbf{X}}_{2}\right)$ and random deviations $\boldsymbol{\delta}$, namely $\left(\mathbf{L}=\mathbf{A}_{2} \hat{\mathbf{X}}_{2}+\boldsymbol{\delta}\right)$, then after performing several transformations, the relation (16) will take the following form:

$$
V\left(\hat{\mathbf{X}}_{2}\right)=\operatorname{cov}\left(\hat{\mathbf{X}}_{2}\right)=\hat{\sigma}_{0}^{2}\left(\mathbf{N}_{2}-\mathbf{N}_{12}^{T} \mathbf{N}_{1}^{-1} \mathbf{N}_{12}\right)^{-1}
$$

when $\hat{\delta}_{0}^{2}$ states for coefficient of variance obtained in the process of vector estimation $\hat{\mathbf{X}}_{1}$ and $\hat{\mathbf{X}}_{2}$.

Random deviations vector $\delta$ to the estimated linear model (2) is a difference of the observed random variables $L$ and its mean value $\mathbf{E}(\mathbf{L})=\mathbf{A}_{1} \hat{\mathbf{X}}_{1}+\mathbf{A}_{2} \hat{\mathbf{X}}_{2}$, namely:

$$
\hat{\boldsymbol{\delta}}=\mathbf{L}-\left[\begin{array}{ll}
\mathbf{A}_{1} & \mathbf{A}_{2}
\end{array}\right]\left[\begin{array}{l}
\hat{\mathbf{X}}_{1} \\
\hat{\mathbf{X}}_{2}
\end{array}\right]
$$


Thus variation coefficient in the estimated model of the tie construction is expressed by the formula:

$$
\hat{\sigma}_{0}^{2}=\frac{\hat{\boldsymbol{\delta}}^{T} \mathbf{G}^{-1} \hat{\boldsymbol{\delta}}}{n-k}
$$

in which $n$ states for the number of observed geodetic elements in the tie construction, and $k$ is a number of estimated coordinates of horizontal and vertical control network points, which are included in the tie construction.

\section{The Criteria of Tying Horizontal and Vertical Control Networks}

Matrix $\mathbf{G}$ represented the variance matrix of the observed values (angles and lenghts) in the geodetic tie construction; therefore it will contain on the main diagonal only the squares of mean measurement errors. Values of those errors are established on the basis of accuracy classes of the instruments used for measuring lenghts and angles in the tie construction. Matrix $\mathbf{G}$ can be written in the following form:

$$
\mathbf{G}=\left[\begin{array}{cccccc}
\sigma_{d 1}^{2} & 0 & 0 & 0 & 0 & 0 \\
0 & \ldots & 0 & 0 & 0 & 0 \\
0 & 0 & \sigma_{d i}^{2} & 0 & 0 & 0 \\
0 & 0 & 0 & \sigma_{\beta 1}^{2} & 0 & 0 \\
0 & 0 & 0 & 0 & \ldots . & 0 \\
0 & 0 & 0 & 0 & 0 & \sigma_{\beta i}^{2}
\end{array}\right]
$$

In practical solutions the mean errors for lenght measurements are accepted at equal level $\sigma_{d}$ and for angle measurement at equal level $\sigma_{\beta}$.

Matrix $\mathbf{C}$ will be represented by covariance matrix for the coordinates of selected national geodetic control network points, included in the tie construction. Matrix $\mathbf{C}$ should come from national geodetic control network adjustment; therefore it should have the following form:

$$
\mathbf{C}=\left[\begin{array}{cccccc}
\sigma^{2}\left(x_{1}\right) & \operatorname{cov}\left(x_{1}, y_{1}\right) & \ldots & \ldots & \operatorname{cov}\left(x_{1}, x_{m}\right) & \operatorname{cov}\left(x_{1}, y_{m}\right) \\
/-/ & \sigma^{2}\left(y_{1}\right) & \ldots & \ldots & \operatorname{cov}\left(y_{1}, x_{m}\right) & \operatorname{cov}\left(y_{1}, y_{m}\right) \\
1-/ & \ldots & \ldots & \ldots & \ldots & \ldots \\
1-/ & \ldots & \ldots & \ldots & \ldots & \ldots \\
1-1 & 1-/ & 1-/ & /-/ & \sigma^{2}\left(x_{m}\right) & \operatorname{cov}\left(x_{m}, y_{m}\right) \\
1-/ & 1-/ & /-/ & /-/ & /-/ & \sigma^{2}\left(y_{m}\right)
\end{array}\right]
$$


If the coordinates of national geodetic control network points do not have full covariance matrix, then matrix $\mathbf{C}$ should contain only the elements on the main diagonal, the values of which should correspond to the squares of mean errors of establishing coordinates of these points.

Matrices $\mathbf{A}_{1}$ and $\mathbf{A}_{2}$ are partial derivative values of the observed elements in the tie construction calculated against the coordinates of points included in this construction.

On the basis of formulas (13) and (14) vector of unknowns is estimated, which contains differentials $d x_{i}, d y_{i}$ to the coordinates of national geodetic control points as well as differentials $d \bar{x}_{i}, d \bar{y}_{i}$ to the approximate coordinates of the horizontal and vertical control points.

According to the existing geodetic intructions, the following accuracy criteria can be mentioned. The $3^{\text {rd }}$ class national geodetic control networks have specified accuracy charactersitics in form of mean error of point location $\sigma_{P}=\sqrt{\sigma_{x}^{2}+\sigma_{y}^{2}} \leq 10 \mathrm{~cm}$. Accuracy of horizontal and vertical control network is formulated with the use of side lenght error, after final adjustment of observation resulst in this control network. Value of this error, depending on an established accuracy of marking out points in the field, cannot be larger than $5 \mathrm{~cm} \mathrm{[5].}$

To formulate the criteria of tying horizontal and vertical control networks to national geodetic control networks the following estimates determined from model (2) will be used: covariance matrix $\operatorname{cov}\left(\hat{\mathbf{X}}_{2}\right)$ for the coordinates of horizontal and vertical control points established according to the formula (17), and variance coefficient $\hat{\sigma}_{0}^{2}$ for the values observed in the tie construction specified with relation (19).

On the basis of the above parameters values, three ways of final coordinates estimations of horizontal and vertical control points can be formulated.

The criteria describing the way of this estimation will be defined with the following parameters:

- maximum value of standard deviation $\sigma_{\max }\left(\hat{d}_{i}\right)$ for any distance $d_{i}$ between the points of horizontal and vertical control network, calculated on the basis of matrix $\operatorname{cov}\left(\hat{\mathbf{X}}_{2}\right)$;

- variance coefficient $\hat{\sigma}_{0}^{2}$ for the values observed in the tie construction;

- mean error $\sigma_{d}$ for length measurement assumed in the matrix G;

- quantil of Student's $t$-distribution $t_{\alpha}$ for $(n-1)$ degrees of freedom and $(1-\alpha)=0.95$ significance level, which takes the following values:

\begin{tabular}{||c|c|c|c|c|c|c|c|c|c|c|c|c|c||}
\hline \hline$n-k$ & 1 & 2 & 3 & 4 & 5 & 6 & 7 & $\ldots$ & 10 & 20 & 30 & $\ldots$ & 100 \\
\hline$t_{\alpha}$ & 12.7 & 4.3 & 3.2 & 2.8 & 2.6 & 2.4 & 2.4 & $\ldots$ & 2.2 & 2.1 & 2.0 & $\ldots$ & 2.0 \\
\hline
\end{tabular}


I. When standard deviations for any distance $d_{i}$ between the points of horizontal and vertical control network, filfill the inequality:

$$
\sigma_{\max }\left(\hat{d}_{i}\right) \leq t_{\alpha} \cdot \hat{\sigma} \cdot \sigma_{d}
$$

then in the final estimation of coordinates of horizontal and vertical control points all elements of the tie construction should be included.

II. If for any distance $d_{i}$ between the horizontal and vertical control points the inequality takes place:

$$
t_{\alpha} \cdot \hat{\sigma} \cdot \sigma_{d}<\sigma_{\max }\left(\hat{d}_{i}\right) \leq 3 \cdot t_{\alpha} \cdot \hat{\sigma} \cdot \sigma_{d}
$$

then the observations of the tie construction should not be included into the final coordinates estimation of the horizontal and vertical control points. In such case, in the final adjustment of the horizontal and vertical control network the estimated coordinates $\hat{\mathbf{X}}_{2}$ should be considered as well as their matrix $\operatorname{cov}\left(\hat{\mathbf{X}}_{2}\right)$.

III. If for any distance $d_{i}$ between the horizontal and vertical control points the inequality takes place:

$$
\sigma_{\max }\left(\hat{d}_{i}\right)>3 \cdot t_{\alpha} \cdot \hat{\sigma} \cdot \sigma_{d}
$$

it means that the value of standard deviation of the distances between the horizontal and vertical control points exceeds triple value of parameters estimation inaccuracy in the model of the tie construction. In such case, tying the horizontal and vertical control network to the national coordinate system should be performed on the basis of estimated coordinates for one point of the national geodetic control network and for one point of the horizontal and vertical control network. Such tying of horizontal and vertical control network will be free of any distortions of measurement results of this control network resulting from high inaccuracy of marking out the national geodetic control network.

\section{Numerical Example}

To establish the way of tying the horizontal and vertical control network, which is represented by one point no. 3 , the tie construction to the national geodetic control network has been analysed, represented by point no. 1 and no. 2 . The elements which are subject to measurement in the tie construction are illustrated in Figure 1, while the observed values of these elements and coordinates of national geodetic control network points, reduced to point no. 1, are presented in Table 1. 


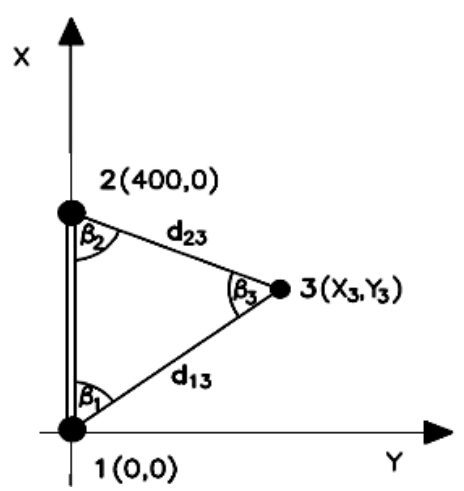

Fig. 1. Tie construction outline of the horizontal and vertical control network

Table 1. Listing of observation results of the elements in the tie construction

\begin{tabular}{|c|c|c|c|c|c|c||}
\hline \multicolumn{2}{||c|}{ National geodetic control network points } & \multicolumn{2}{|c|}{ Measured lenghts } & \multicolumn{2}{c|}{ Measured angles } \\
\hline $\begin{array}{c}\text { point } \\
\text { number }\end{array}$ & $X[\mathrm{~m}]$ & $Y[\mathrm{~m}]$ & denotation & {$[\mathrm{m}]$} & denotation & {$\left[{ }^{\mathrm{g}}\right]$} \\
\hline \hline 1 & 0 & 0 & $d_{13}$ & 370.674 & $\beta_{1}$ & 52.4480 \\
\hline 2 & 400.000 & 0 & $d_{23}$ & 309.749 & $\beta_{2}$ & 68.2358 \\
\hline 3 & - & - & - & - & $\beta_{3}$ & 79.3172 \\
\hline
\end{tabular}

On the basis of the observed elements, that is length $d_{13}$ and angle $\beta_{1}$ as well as the coordinates of the national geodetic control points, the approximate coordinates of point no. 3 have been calculated, that is:

$$
\begin{aligned}
& \bar{x}_{3}=x_{1}+d_{13} \cdot \cos \left(\beta_{1}\right)=251.836[\mathrm{~m}] \\
& \bar{y}_{3}=y_{1}+d_{13} \cdot \sin \left(\beta_{1}\right)=271.989[\mathrm{~m}] .
\end{aligned}
$$

Values of approximate coordinates of point no. 3 and the coordinates of national geodetic control points no. 1 and no. 2 are the basis for calculating the approximate values of the measured values in the tie construction, namely:

- for sides length:

$$
\begin{aligned}
& \bar{d}_{23}=\sqrt{\left(\bar{x}_{3}-x_{2}\right)^{2}+\left(\bar{y}_{3}-y_{2}\right)^{2}}=309.726_{6}[\mathrm{~m}], \\
& \bar{d}_{13}=\sqrt{\left(\bar{x}_{3}-x_{1}\right)^{2}+\left(\bar{y}_{3}-y_{1}\right)^{2}}=370.674_{2}[\mathrm{~m}]
\end{aligned}
$$


- for angles:

$$
\begin{aligned}
& \cos \left(\bar{\beta}_{1}\right)=\frac{\left(\bar{d}_{13}\right)^{2}+\left(d_{12}\right)^{2}-\left(\bar{d}_{23}\right)^{2}}{2 \cdot \bar{d}_{13} \cdot d_{12}} \Rightarrow \bar{\beta}_{1}=52.4480\left[{ }^{\mathrm{g}}\right] \\
& \cos \left(\bar{\beta}_{2}\right)=\frac{\left(\bar{d}_{12}\right)^{2}+\left(d_{23}\right)^{2}-\left(\bar{d}_{13}\right)^{2}}{2 \cdot \bar{d}_{23} \cdot d_{12}} \Rightarrow \beta_{2}^{O}=68.2455\left[{ }^{\mathrm{g}}\right] \\
& \cos \left(\bar{\beta}_{3}\right)=\frac{\left(\bar{d}_{23}\right)^{2}+\left(\bar{d}_{13}\right)^{2}-\left(\bar{d}_{12}\right)^{2}}{2 \cdot \bar{d}_{23} \cdot \bar{d}_{13}} \Rightarrow \bar{\beta}_{3}=79.3066\left[{ }^{\mathrm{g}}\right] .
\end{aligned}
$$

On the basis of the above values the observational equations system was formulated, illustrated in Table 2.

Table 2. Observation equations for the tie construction of the setting out network

\begin{tabular}{|c|c|c|c|c|c|c|c|c|}
\hline $\begin{array}{c}\text { Denotation } \\
\text { of the } \\
\text { element }\end{array}$ & $d x_{1}$ & $d y_{1}$ & $d x_{2}$ & $d y_{2}$ & $d \bar{x}_{3}$ & $d \bar{y}_{3}$ & $\begin{array}{c}\text { Calculation of the } \\
\text { constant terms }\end{array}$ & $\begin{array}{c}\text { Constant } \\
\text { terms }\end{array}$ \\
\hline \hline$d_{13}$ & -0.679 & -0.734 & 0 & 0 & 0.679 & 0.734 & $370.674-370.674$ & $0[\mathrm{~mm}]$ \\
\hline$d_{23}$ & 0 & 0 & 0.478 & -0.878 & -0.478 & 0.878 & $309.749-309.727$ & $22[\mathrm{~mm}]$ \\
\hline$\beta_{1}$ & 1.260 & 0.425 & 0 & -1.592 & -1.260 & 1.167 & $52.4480-52.4480$ & $0\left[{ }^{c c}\right]$ \\
\hline$\beta_{2}$ & 0 & -1.592 & -1.805 & 0.609 & 1.805 & 0.983 & $68.2358-68.2455$ & $-97\left[^{c c}\right]$ \\
\hline$\beta_{3}$ & -1.260 & 1.167 & 1.805 & 0.983 & -0.545 & -2.150 & $79.3172-79.3066$ & $106\left[{ }^{c c}\right]$ \\
\hline & \multicolumn{7}{c}{$\mathbf{A}_{1}$} & \multicolumn{3}{c}{$\mathbf{A}_{2}$} & & $\mathbf{L}$ \\
\hline
\end{tabular}

In the composed system of observational equations the matrices $\mathbf{A}_{1}, \mathbf{A}_{2}$ and $\mathbf{L}$ have been marked in relevant frames.

To determine matrix $\mathbf{G}$ it was assumed that the measurement is carried out with the electronic tachymeter, which according to the accuracy metrics provided $\sigma_{d}=5 \mathrm{~mm}$ and $\sigma_{\beta}=10^{\mathrm{cc}}$. Matrix $\mathrm{G}$ will therefore contain the following elements:

$$
\mathbf{G}=\left[\begin{array}{ccccc}
25 & 0 & 0 & 0 & 0 \\
0 & 25 & 0 & 0 & 0 \\
0 & 0 & 100 & 0 & 0 \\
0 & 0 & 0 & 100 & 0 \\
0 & 0 & 0 & 0 & 100
\end{array}\right]\left[\mathrm{mm}^{2} \cup \mathrm{cc}^{2}\right]
$$


Matrix $\mathbf{C}$ will be represented by covariance matrix for the coordinates of the $3^{\text {rd }}$ class detailed control points, which in the tie construction are points no. 1 and no. 2. Matrix $\mathbf{C}$ comes from the adjustment of this control network and contains the following elements:

$$
C=\left[\begin{array}{cccc}
2500 & 420 & 810 & -350 \\
420 & 2120 & 460 & 280 \\
810 & 460 & 2340 & -620 \\
-350 & 280 & -620 & 2670
\end{array}\right]\left[\mathrm{mm}^{2}\right]
$$

On the basis of values of the elements on the diagonal it can be seen that standard deviations of the coordinates of the detailed control network points fit within the range of $46-52 \mathrm{~mm}$. Carrying out the defined matrix operations according to the formula (5), we get the following values of the defined matrix elements:

$$
\begin{aligned}
\mathbf{N}_{1}=\left[\begin{array}{cccc}
0.050654 & 0.010520 & -0.022880 & -0.032410 \\
/-/ & 0.062838 & 0.049698 & 0.005076 \\
/-/ & /-/ & 0.074825 & -0.009922 \\
/-/ & /-/ & /-/ & 0.069967
\end{array}\right], \\
\mathbf{N}_{2}=\left[\begin{array}{cc}
0.079008 & 0.017904 \\
/-/ & 0.121892
\end{array}\right] \\
\mathbf{N}_{12}=\left[\begin{array}{cc}
-0.027451 & 0.021859 \\
-0.060386 & -0.057330 \\
-0.051557 & -0.039763 \\
0.042482 & -0.064562
\end{array}\right] .
\end{aligned}
$$

Symbol /-/ used in the above matrices means the element symetrical towards main diagonal.

After carrying out the formulas (8)-(10) the elements of matrices $\mathbf{H}_{1}, \mathbf{H}_{2}$ and $\mathbf{H}_{12}$ are determined, which are the basis of estimation of vector of unknowns and their covariance matrices, namely:

$$
\mathbf{H}_{1}=\left[\begin{array}{cccc}
1620.8762 & 440.6347 & 1605.7276 & -490.2178 \\
/-/ & 2119.5142 & 441.3215 & 283.2931 \\
/-/ & /-/ & 1619.7560 & -493.0819 \\
/-/ & /-/ & /-/ & 2647.6330
\end{array}\right] \quad\left[\mathrm{mm}^{2}\right]
$$




$$
\begin{aligned}
& \mathbf{H}_{2}=\left[\begin{array}{cc}
4840.2818 & -697.2068 \\
/-/ & 1481.8406
\end{array}\right]\left[\mathrm{mm}^{2}\right], \\
& \mathbf{H}_{12}=\left[\begin{array}{cc}
2245.13 & -149.04 \\
1690.36 & 963.59 \\
2249.86 & -143.64 \\
-2100.26 & 1771.20
\end{array}\right]\left[\mathrm{mm}^{2}\right] .
\end{aligned}
$$

Differentials estimate to the coordinates of the national geodetic control points, which are represented by points no. 1 and no. 2 , is expressed by the following dependence (compare formula (13)):

$$
\hat{\mathbf{X}}_{1}=\left[\begin{array}{ccccc}
-0.3681 & -0.2433 & 0.0720 & 0.0759 & -0.1479 \\
0.0045 & 0.0104 & -0.0035 & 0.0002 & 0.0038 \\
0.3204 & 0.2247 & -0.0669 & -0.0672 & 0.1341 \\
-0.0518 & -0.0452 & 0.0139 & 0.0100 & -0.0240
\end{array}\right] \times\left[\begin{array}{c}
0 \\
22 \\
0 \\
97 \\
106
\end{array}\right]=\left[\begin{array}{c}
-28 \\
1 \\
25 \\
-5
\end{array}\right][\mathrm{mm}] .
$$

Differentials estimate to the coordinates of the horizontal and vertical control points, represented by point no. 3, will be expressed by the formula (14) in form of the following dependence:

$$
\hat{\mathbf{X}}_{2}=\left[\begin{array}{ccccc}
03854 & -0.2432 & -0.2104 & 0.2007 & 0.0098 \\
0.3276 & 0.4218 & 0.0976 & 0.0208 & -0.1185
\end{array}\right] \times\left[\begin{array}{c}
0 \\
22 \\
0 \\
97 \\
106
\end{array}\right]=\left[\begin{array}{c}
-24 \\
-5
\end{array}\right][\mathrm{mm}] .
$$

On the basis of the above estimate values the formula (18) will be realised, which will lead to the calculation of random deviations to the observed elements of the tie construction, namely:

$$
\delta=\mathbf{L}-\left[\begin{array}{ll}
\mathbf{A}_{1} & \mathbf{A}_{2}
\end{array}\right]\left[\begin{array}{l}
\hat{\mathbf{X}}_{1} \\
\hat{\mathbf{X}}_{2}
\end{array}\right]=\left[\begin{array}{c}
1.7 \\
-1.4 \\
2.5 \\
1.0 \\
5.5
\end{array}\right][\mathrm{mm} \cup \mathrm{cc}] .
$$


On the basis of the determined random deviations $\boldsymbol{\delta}$ and demanded matrix $\mathbf{G}$ variance coefficient (19) has been calculated for the assumed estimation model, that is:

$$
\hat{\sigma}_{0}^{2}=\frac{\boldsymbol{\delta}^{T} \mathbf{G}^{-1} \boldsymbol{\delta}}{n-k}=\frac{0.5707}{3}=0.19 .
$$

Standard deviation value of the estimated model in the tie construction amounts to:

$$
\hat{\sigma}_{0}=\sqrt{0.19}=0.44
$$

and that means that the mutual concordance of the tie construction of the setting out network, obtained in the estimation process, is at the level of $44 \%$ of the assumed accuracy of the observed elements.

The value of variance coefficient $\hat{\sigma}_{0}^{2}$ proves that geodetic measurements performed in the tie construction of the setting out network present high mutual concordance and are on the accuracy level:

$$
\begin{gathered}
\sigma[d]=\hat{\sigma}_{0} \cdot \sigma_{d}=0.44 \cdot 5 \mathrm{~mm}=2.2 \mathrm{~mm} . \\
\sigma[\beta]=\hat{\sigma}_{0} \cdot \sigma_{\beta}=0.44 \cdot 10^{\mathrm{cc}}=4.4^{\mathrm{cc}} .
\end{gathered}
$$

Estimate $\mathbf{X}_{2}$ proves, that the most probable value of the coordinates of point no. 3 in the national system are as follows:

$$
\left[\begin{array}{l}
\hat{x}_{3} \\
\hat{y}_{3}
\end{array}\right]=\left[\begin{array}{l}
\bar{x}_{3} \\
\bar{y}_{3}
\end{array}\right]+\left[\begin{array}{l}
d \bar{x}_{3} \\
d \bar{y}_{3}
\end{array}\right]=\left[\begin{array}{l}
251.836 \\
271.989
\end{array}\right]+\left[\begin{array}{l}
-0.024 \\
-0.005
\end{array}\right]=\left[\begin{array}{l}
251.812 \\
271.984
\end{array}\right][\mathrm{m}] .
$$

Covariance matrix for the estimated coordinates of point no. 3 will be expressed by the following dependence:

$$
\operatorname{cov}\left[\begin{array}{l}
\hat{x}_{3} \\
\hat{y}_{3}
\end{array}\right]=\hat{\sigma}_{0}^{2} \times \mathbf{H}_{2}=0.19 \times\left[\begin{array}{cc}
4840.2818 & -697.2068 \\
/-/ & 1481.8406
\end{array}\right]=\left[\begin{array}{cc}
919.65 & -132.46 \\
-132.46 & 281.55
\end{array}\right]\left[\mathrm{mm}^{2}\right]
$$

The above calculations show that standard deviations of the estimated coordinates of point no. 3 have the following values:

$$
\begin{aligned}
& \sigma\left[\hat{x}_{3}\right]=\sqrt{919.65}=30 \mathrm{~mm}, \\
& \sigma\left[\hat{y}_{3}\right]=\sqrt{281.55}=17 \mathrm{~mm} .
\end{aligned}
$$


In the analysed numerical example only one point was considered of the horizontal and vertical control network in the tie construction, therefore to determine accuracy criterion of tying larger value of standard deviation will be used, calculated for the side $1-3$ or $2-3$.

After considering the azimuth of this side $A_{1-3}=52.448^{\mathrm{g}}$ the standard deviation is $\sigma\left(\hat{d}_{1-3}\right)=22.6 \mathrm{~mm}$, and for the azimuth $A_{2-3}=131.764^{\mathrm{g}}$ standard deviation is $\sigma\left(\hat{d}_{2-3}\right)=23.2 \mathrm{~mm}$. For further analyses the value $\sigma_{\max }\left(\hat{d}_{2-3}\right)=23 \mathrm{~mm}$ is assumed. Variance coefficient for the values observed in the tie construction is $\hat{\sigma}_{0}^{2}=0.19$, which corresponds to $\hat{\sigma}_{0}=0.44$. Mean error for lenght measurements assumed in the matrix $\mathbf{G}$ is $\sigma_{d}=5 \mathrm{~mm}$. Quantil of Student's t-distribution for $(n-k)=3$ degrees of freedom and for $(1-\alpha)=0.95$ significance level, is $t_{\alpha}=3.2$.

After fulfilling the accuracy criterion (25) we get the following inequality:

$$
\sigma_{\max }\left(\hat{d}_{i}\right)>3 \cdot t_{\alpha} \cdot \hat{\sigma} \cdot \sigma_{d} \Rightarrow 23>3 \cdot 3.2 \cdot 0.44 \cdot 5 \Leftrightarrow 23>21 .
$$

The above calculations prove that tying the horizontal and vertical control network to the national coordinate system should be performed on the basis of estimated coordinates for one point of the national geodetic control network, e.g no. 1, and for one point of the horizontal and vertical control network. For final estimation of the coordinates of the horizontal and vertical control points in the national system the orientation elements of this control network should be assumed, which result from the estimated coordinates in the tie model, namely:

$$
\left[\begin{array}{l}
\hat{x}_{3} \\
\hat{y}_{3}
\end{array}\right]=\left[\begin{array}{l}
251.812 \\
271.984
\end{array}\right][\mathrm{m}], \quad\left[\begin{array}{l}
\hat{x}_{1} \\
\hat{y}_{1}
\end{array}\right]=\left[\begin{array}{c}
-0.028 \\
0.001
\end{array}\right][\mathrm{m}] .
$$

The established method of tying of horizontal and vertical control network will be free of any distortions of measurement results of this control network because of high inaccuracy of marking out the coordinates of the national geodetic control network points.

\section{Final Conclusions}

The derived formulas for parameters estimation in the tie construction are the basis for formulating three ways of final estimations of the coordinates of the horizontal and vertical control points in the national coordinates system. The criteria describing the way of this estimation are defined with the following parameters: $\operatorname{cov}\left(\hat{\mathbf{X}}_{2}\right) \Rightarrow \sigma_{\max }\left(\hat{d}_{i}\right), \wedge, \sigma_{d}$ and $t_{\alpha}$. 
If the inequality $\sigma_{\max }\left(\hat{d}_{i}\right) \leq t_{\alpha} \cdot \hat{\sigma} \cdot \sigma_{d}$ occurs, then in the final estimation of the coordinates of the horizontal and vertical control points all elements of the tie construction should be included.

If the estimated parameters fulfil the inequality $t_{\alpha} \cdot \hat{\sigma} \cdot \sigma_{d}<\sigma_{\max }\left(\hat{d}_{i}\right) \leq 3 \cdot t_{\alpha} \cdot \hat{\sigma} \cdot \sigma_{d^{\prime}}$ then in the process of tying the estimated coordinates of the horizontal and vertical control points $\left(\hat{\mathbf{X}}_{2}\right)$ and their matrix $\operatorname{cov}\left(\hat{\mathbf{X}}_{2}\right)$ should be considered.

In case when for any distance $d_{i}$ between the points of the horizontal and vertical control network the inequality $\sigma_{\max }\left(\hat{d}_{i}\right)>3 \cdot t_{\alpha} \cdot \hat{\sigma} \cdot \sigma_{d}$ occurs, tying the horizontal and vertical control network to the national coordinate system should be performed on the basis of estimated coordinates for one point of the national geodetic control network and for one point of the horizontal and vertical control network.

To conclude, it should be emphasized that the proposed algorithm can be used in practice for marking out single structures or sets of structures in small areas as well as to mark out border markers of the residential plots in the field.

\section{References}

[1] Adamczewski Z.: Rachunek wyrównawczy w 15 wykładach. Oficyna Wydawnicza Politechniki Warszawskiej, Warszawa 2007.

[2] Baarda W.: S-Transformations and criterion matrices. Netherlands Geodetic Commission, Publications on Geodesy, New Series vol. 5, no. 1, Rijkscommissie voor Geodesie, Delft 1973.

[3] Baran W.: Teoretyczne podstawy opracowania wyników pomiarów geodezyjnych. WN PWN, Warszawa 1999.

[4] Chrzanowski A.: Optimation of the breakthrough accurrancy in tunneling surveyes. The Canadian Surveyer, vol. 35, no. 1981, pp. 5-16.

[5] Czaja J.: Wybrane zagadnienia z geodezji inżynieryjnej. Wydawnictwa AGH, Kraków 1996.

[6] Czaja J.: Modele statystyczne w informacji o terenie. Wydawnictwa AGH, Kraków 1997.

[7] Gaździcki J.: Analiza dokładności poziomych sieci geodezyjnych. Prace Instytutu Geodezji i Kartografii, 5, 1976.

[8] Kadaj R.: GEONET. Pakiet programów obliczeniowych. 1995.

[9] Kamiński W.: Odporna estymacja bayesowska w wyrównaniu sieci geodezyjnych. Wydawnictwo Uniwersytetu Warmińsko-Mazurskiego, Olsztyn 2000.

[10] Pelzer H.: Zur Behandlung singularer Ausgleichungsaufgaben. Zeitschrift für Vermessungswesen, heft 5, 1974, pp. 181-194.

[11] Prószyński W.: Accuracy analysis for non-distorting connection of engineering survey networks. [in:] XVIII International Congress of Surveyors, June 1 to 11, 1986, Toronto, Canada, Canadian Institute of Surveying, Ottawa 1986. 
[12] Prószyński W., Kwaśniak M.: Podstawy geodezyjnego wyznaczania przemieszczeń. Pojęcia i elementy metodyki. Oficyna Wydawnicza Politechniki Warszawskiej, Warszawa 2006.

[13] Rao C.: Modele liniowe statystyki matematycznej. PWN, Warszawa 1982.

[14] Teunissen P.J.G.: Adjustment theory - an introduction. Mathematical Geodesy and Positioning, VSSD, Delft, The Netherlands 2000.

[15] Wiśniewski Z.: Algebra macierzy i statystyka matematyczna w rachunku wyrównawczym. Wydawnictwo Uniwersytetu Warmińsko-Mazurskiego, Olsztyn 2000.

[16] Wiśniewski Z.: Rachunek wyrównawczy w geodezji (z przykładami). Wydawnictwo Uniwersytetu Warmińsko-Mazurskiego, Olsztyn 2005 